\title{
CLIMATE SENSITIVITY: THE SIGNIFICANCE OF THE ALTITUDE-MASS- BALANCE FEEDBACK ON GLACIERS AND ICE SHEETS
}

\section{(Abstract)}

\author{
by \\ Anne Letréguilly \\ (Alfred-Wegener-Institut für Polar- und Meeresforschung, Postfach 120161,
} D-2850 Bremerhaven, Federal Republic of Germany)

and

Johannes Oerlemans

(Institute of Meteorology and Oceanography, University of Utrecht, The Netherlands)

\begin{abstract}
An ice mass increasing its extent will generally also increase its mean surface elevation (anything else being unchanged). Since temperature drops rapidly with height this of ten implies a more positive mass balance and thus further growth. This powerful feedback loop is at least as important as the temperature-albedo feedback. In this work, we present a general study of the nature of the altitude-massbalance feedback, with special attention for the role of differences in the bedrock geometry. One- and twodimensional experiments on various bedrock topographies are run, using a numerical ice-sheet model based on plane shear flow of ice. Different climates are simulated by lowering or raising uniformly the mass-balance distribution over the ice sheet.
\end{abstract}

These studies were first done on steady state ice sheets. They show that some geometries can largely enhance this altitude mass-balance feedback. On an island, for instance, it is possible to have two different stable steady states under the same climatic environment: no ice sheet, or a large one over the whole island. When the geometry of the island becomes more complex, for instance with two hills of unequal heights, four different equilibria can be found for the same climatic conditions: no ice sheet, one small one, two small ones or a very large one. Which will develop depends entirely on the history of the mass-balance fluctuations.

\section{A EURASIAN ICE-SHEET STUDY USING A COMBINED ICE-SHEET/ ICE-SHELF NUMERICAL MODEL \\ (Abstract)}

by

\section{Dean R. Lindstrom}

(Department of the Geophysical Sciences, University of Chicago, 5734 South Ellis Avenue, Chicago, IL 60637, U.S.A.)

A numerical model which simultaneously computes grounded and ice-shelf flow was used to develop an equilibrium ice-sheet-ice-shelf system over Eurasia and the Arctic region. Present-day net accumulation rates and mean annual and July temperature values were used as base values for climatic variable specifications. The values were adjusted during the model run to account for changes in the ice-surface elevation and atmospheric $\mathrm{CO}_{2}$ concentration. The model-determined equilibrium ice-sheet configuration was used as input for additional runs to observe what effect removing the Arctic ice shelf and increasing the $\mathrm{CO}_{2}$ con- centration from glacial to present-day values has on the ice sheet.

At equilibrium, an ice shelf formed over the Arctic Ocean and Greenland and Norwegian seas. Ice easily grounded over the Barents, Kara, East Siberian, and Laptev seas. The grounded ice-sheet profile differs in Europe from most glacial geological reconstructions because the North Atlantic Current effect was not removed from the climatic adjustments. As a result, ice did not extend over the North Sea and onto the British Isles because of the North Atlantic Current's warming effect. Also, the precipitation rate over Europe was too high because of the moisture source the North Atlantic Current carries, and the ice sheet expanded beyond the field-determined ice-sheet margins in the region south-east of Finland.

Removing most of the Arctic region's ice-shelf cover had little effect on the grounded ice sheet unless it rested upon a deformable sediment layer. The ice sheet was able to collapse within 10000 years, however, when the $\mathrm{CO}_{2}$ concentration was gradually increased toward present-day values using the Vostok ice core's $\mathrm{CO}_{2}$ record from the last 18000 years. Initially, most mass loss resulted from surface melting. Once the thickness decreased enough over some regions for the grounded ice to become ungrounded, however, most mass loss resulted from the ice shelf rapidly transporting the ice to the ice-shelf front and discharging it to the sea. 